\title{
Membranoproliferative glomerulonephritis presenting as arthropathy and cardiac valvulopathy in hypocomplementemic urticarial vasculitis: a case report
}

\author{
Chuiyoung Park', Seung Won Choi ${ }^{1}$, Misung Kim², Jongha Park', Jong Soo Lee ${ }^{1}$ and Hyun Chul Chung ${ }^{1 *}$
}

\begin{abstract}
Introduction: Hypocomplementemic urticarial vasculitis syndrome is a rare disorder characterized by chronic urticarial vasculitis, arthralgia, arthritis, and hypocomplementemia. Previously, only six patients with concomitant hypocomplementemic urticarial vasculitis syndrome, Jaccoud's arthropathy, and valvular heart disease have been reported.

Case presentation: A 30-year-old Korean man presented with hypocomplementemic urticarial vasculitis syndrome. In addition to urticarial cutaneous lesions, he experienced polyarthralgia and arthritis that resulted in progressive deformity of the joints of both hands, cardiac valvulopathy with mitral, tricuspid, and aortic regurgitation, and intermittent neck swelling with laryngeal edema. He also developed nephritis with azotemia. His renal biopsy results revealed membranoproliferative glomerulonephritis, type I. He showed a partial response to a combination therapy of steroid, cyclophosphamide, and mycophenolate mofetil.

Conclusions: We describe, to the best of our knowledge, the first case of glomerulonephritis presenting a arthropathy and cardiac valvulopathy in hypocomplementemic urticarial vasculitis syndrome. A combination of corticosteroids, cyclophosphamide, and mycophenolate mofetil appear to be a safe and effective treatment for nephropathy, however are less effective for cutaneous vasculitis, cardiac valvulopathy, and arthropathy.
\end{abstract}

Keywords: Hypocomplementemic urticarial vasculitis syndrome, Arthropathy, Valvulopathy, Membranoproliferative glomerulonephritis

\section{Introduction}

Hypocomplementemic urticarial vasculitis syndrome (HUVS) is a rare disorder characterized by chronic urticarial vasculitis, arthralgia, arthritis, and activation of the classical complement pathway. Most patients have autoantibodies to $\mathrm{C} 1 \mathrm{q}$ [1]. Previously, only six patients with concomitant HUVS, Jaccoud's arthropathy, and valvular heart disease have been reported [2-5]. In this case, we describe a 30-year-old Korean man with this rare combination of symptoms, as well as azotemia secondary to membranoproliferative glomerulonephritis.

\footnotetext{
* Correspondence: hcjungmd@uuh.ulsan.kr

'Department of Internal Medicine, Ulsan University Hospital, 290-3

Jeonha-dong, Dong-gu, Ulsan 682-714, Republic of Korea

Full list of author information is available at the end of the article
}

\section{Case presentation}

A 30-year-old Korean man presented to our hospital with recurrent urticarial lesions and joint pain for one year previous. The urticarial lesions resolved with hyperpigmentation or residual purpura. The arthralgias were intermittent and migratory, affecting the hands, knees, and ankles, and resolved spontaneously after 2 to 3 days. He did not smoke, denied any use of alcohol or herbal remedies, and had no family history of autoimmune disease. On examination diffusely scattered, variably sized erythematous pruritic papules were noted on his trunk and extremities. Laboratory test results revealed his levels of blood urea nitrogen (BUN) to be $12.3 \mathrm{mg} / \mathrm{dL}$, serum creatinine $1.09 \mathrm{mg} / \mathrm{dL}, \mathrm{C}$-reactive protein $1.167 \mathrm{mg} / \mathrm{L}$, and rheumatoid factor $(\mathrm{RF})<2.5 \mathrm{IU} / \mathrm{mL}$ (normal range between 
0 and $14 \mathrm{IU} / \mathrm{mL}$ ). He was found to be negative for anticyclic citrullinated peptide antibody (anti-CCP), antinuclear antibodies (ANA) titer 1:40, speckled type, and the HLA-B27 genotype was negative, and his erythrocyte sedimentation rate (ESR) was $21 \mathrm{~mm} / \mathrm{h}$. No cartilage or bone destruction was detected on radiographs of his hands. He was diagnosed with rheumatoid factor-negative rheumatoid arthritis with skin vasculitis and was treated with prednisolone, hydroxychloroquine, methotrexate, and non-steroidal anti-inflammatory drugs.

Two years after his initial visit, he was admitted to our hospital due to a worsening skin rash, right flank pain, and upper abdominal pain unresponsive to medication. His blood pressure was $148 / 80 \mathrm{~mm} \mathrm{Hg}$, his heart rate was regular at 76 beats/min, and his body temperature was $36.3^{\circ} \mathrm{C}$. He had diffuse urticarial lesions on his face, trunk, and upper arms (Figure 1). A skin biopsy of a new urticarial lesion revealed leukocytoclastic vasculitis. An abdominal computed tomography (CT) scan revealed multifocal low-attenuated lesions in both kidneys without other abnormalities. A laboratory workup showed

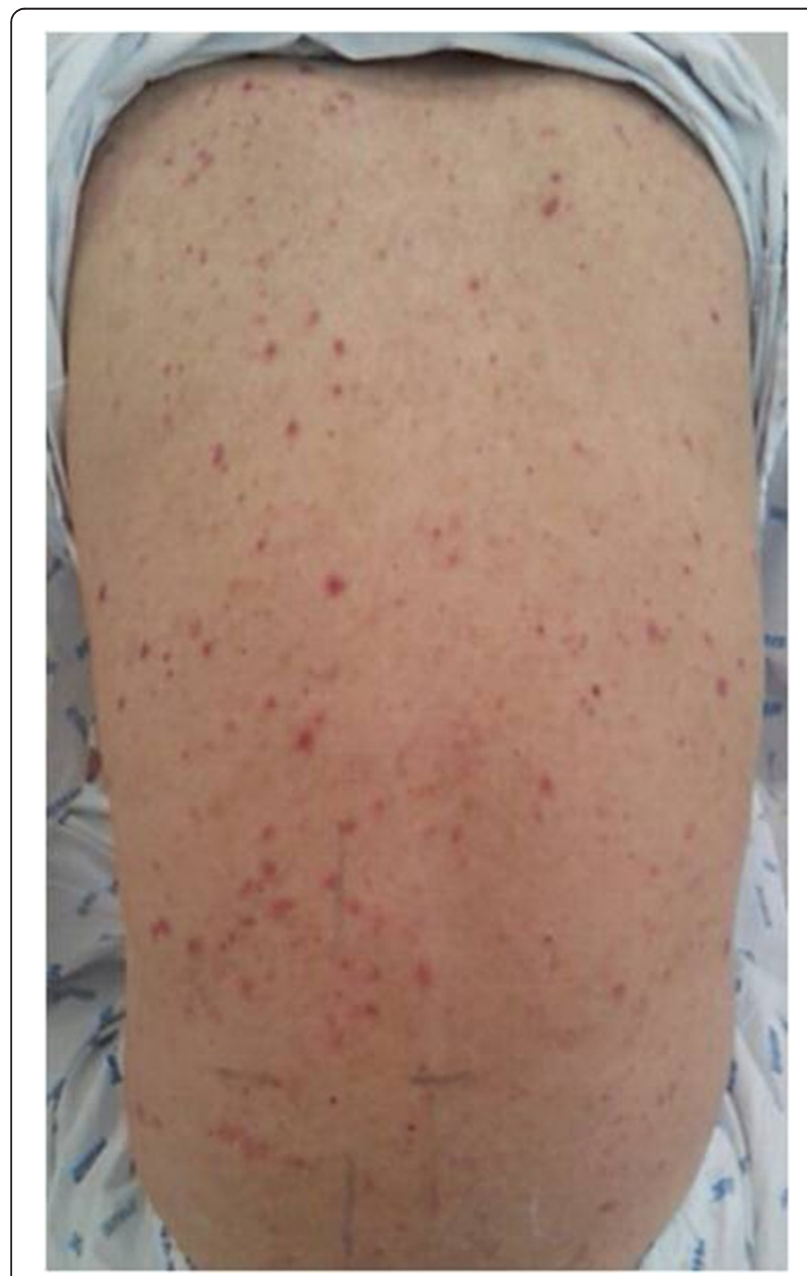

Figure 1 Urticarial rash and hyperpigmentation. his levels of total protein to be $5.7 \mathrm{~g} / \mathrm{dL}$, albumin $3.3 \mathrm{~g} / \mathrm{dL}$, BUN $21 \mathrm{mg} / \mathrm{dL}$, creatinine $1.38 \mathrm{mg} / \mathrm{dL}$, D-dimer $3.5 \mu \mathrm{g} / \mathrm{mL}$ (normal range, 0 to $1 \mu \mathrm{g} / \mathrm{mL}$ ), fibrinogen $481 \mathrm{mg} / \mathrm{dL}$ (normal range, 200 to $400 \mathrm{mg} / \mathrm{dL}$ ), lactate dehydrogenase 751IU/L (normal range 218 to $472 \mathrm{IU} / \mathrm{L}$ ), C-reactive protein $5.261 \mathrm{mg} / \mathrm{L}$, normal prothrombin time and activated partial thromboplastin time; antithrombin III 90\% (normal range, 80 to $120 \%$ ), normal protein $\mathrm{C}$ and $\mathrm{S}$ activities, and his ESR was $31 \mathrm{~mm} / \mathrm{h}$.

He was found to be negative for ANA, anti-doublestranded DNA antibody, anti-Smith antibody, anti-SS-A/ SS-B, lupus anticoagulant, antistreptolysin $\mathrm{O}$, and antineutrophil cytoplasmic antibody (ANCA). The concentrations of serum IgG, IgA, and IgM were normal. His C3 level was $12.2 \mathrm{mg} / \mathrm{dL}$ (normal range 90 to $180 \mathrm{mg} / \mathrm{dL}$ ), C4 level $<1.5 \mathrm{mg} / \mathrm{dL}$ (normal range 10 to $40 \mathrm{mg} / \mathrm{dL}$ ), and $\mathrm{CH} 50$ level $4.2 \mathrm{U} / \mathrm{mL}$ (normal range 23 to $46 \mathrm{U} / \mathrm{mL}$ ), and his cryoglobulin test result was negative. His serological test results for hepatitis $B$ and $C$ viruses were also negative. His urine analysis showed trace protein, red blood cell (RBC) count 0 to $1 /$ high-power field (HPF), and a urine protein-creatinine ratio of $364.4 \mathrm{mg} / \mathrm{g}$. A chest radiograph showed no abnormalities. An echocardiogram showed moderate mitral and tricuspid regurgitation with moderate-to-severe aortic regurgitation. There was diastolic left ventricular dysfunction and normal left ventricular systolic function. An aortography, superior mesenteric, celiac, and bilateral renal arteriography revealed no abnormalities. High-dose oral prednisolone $(1 \mathrm{mg} / \mathrm{kg})$ was administered for the treatment of active vasculitis. His abdominal pain and skin lesions subsequently improved.

One year after continuous treatment with steroid and azathioprine therapy, he was readmitted due to bouts of repeated deep neck swelling, laryngeal edema, and fever. Symptoms were alleviated with antibiotics and fluid therapy, but no causative organism was identified. After his fever resolved, he developed slow progressive azotemia, proteinuria, and microscopic hematuria. An examination revealed swelling of the proximal interphalangeal joints of both hands with swan neck and flexion deformities (Figure 2). His laboratory tests showed his hemoglobin level to be $8.8 \mathrm{~g} / \mathrm{dL}$, white blood cell count $4340 / \mu \mathrm{L}$ (neutrophils $71 \%$ ), platelet count $56 \times 103 / \mu \mathrm{L}$, total protein level $6.0 \mathrm{~g} / \mathrm{dL}$, albumin level $3.1 \mathrm{~g} / \mathrm{dL}$, BUN level $22 \mathrm{mg} / \mathrm{dL}$, creatinine level $1.99 \mathrm{mg} / \mathrm{dL}$, and C-reactive protein level $2.875 \mathrm{mg} / \mathrm{L}$. His C3 level was $9.0 \mathrm{mg} / \mathrm{dL}$ (normal range 90 to $180 \mathrm{mg} / \mathrm{dL}$ ), C4 level was $<1.5 \mathrm{mg} / \mathrm{dL}$ (normal range 10 to $40 \mathrm{mg} / \mathrm{dL}$ ), $\mathrm{CH} 50$ level was $<2.0 \mathrm{U} / \mathrm{mL}$ (normal range 23 to $46 \mathrm{U} / \mathrm{mL}$ ), and C1q level was $5.02 \mathrm{mg} / \mathrm{dL}$ (normal range 11.8 to $23.8 \mathrm{mg} / \mathrm{dL}$ ). A urine analysis showed protein $1+$, red blood cell count 1 to 3/high-power field (HPF), and urine protein-creatinine ratio of $1470.6 \mathrm{mg} / \mathrm{g}$. The 24 -hour urine protein level was $1.6 \mathrm{~g} /$ day. A percutaneous renal 


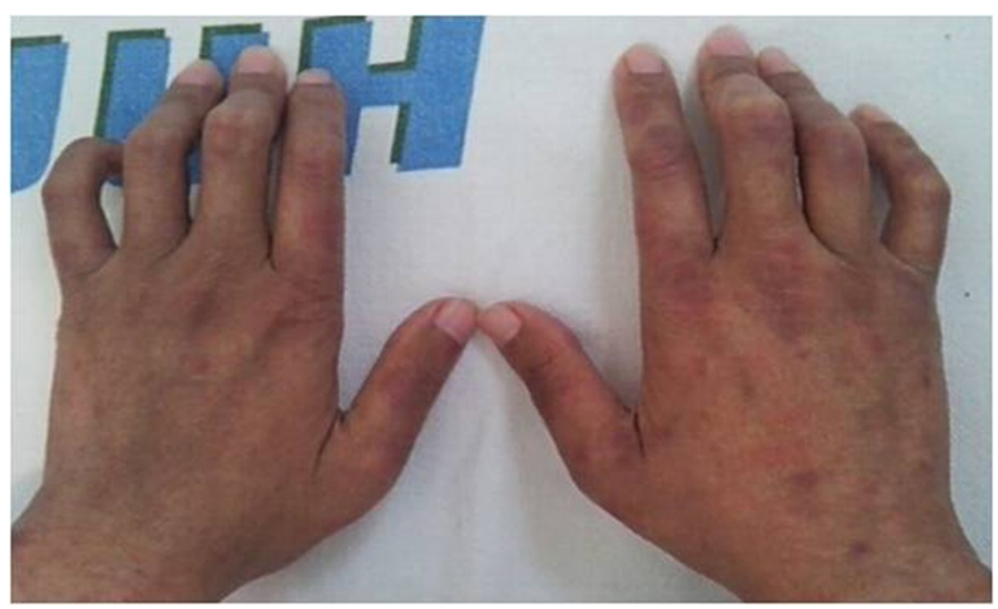

Figure 2 Swelling of the proximal interphalangeal joints with swan neck and flexion deformities of both hands.

biopsy was performed; the specimen for light microscopy contained 12 glomeruli and 2 arteries up to interlobular size. The glomeruli were enlarged. The mesangium was focally expanded due to an increase of the matrix without hypercellularity and the glomerular capillary walls were mildly thickened. There were patchy areas of interstitial inflammation with mostly mononuclear cells and fibrosis. The tubules showed degenerative changes of the epithelial cells with proteinaceous casts and atrophy and the blood vessels showed arteriolosclerosis. Immunofluorescent staining revealed granular deposits of $\operatorname{IgG}(++), \operatorname{IgM}(+), \mathrm{C} 3(+/-)$, $\mathrm{C} 1 \mathrm{q}(+/-)$, and $\mathrm{C} 4 \mathrm{~d}(+++)$ along the capillary loop. An electron microscopy revealed some irregular electron dense deposits in the subendothelial and paramesangial space. His renal biopsy results were compatible with membranoproliferative glomerulonephritis type I (MPGN type I) (Figure 3A,B). He was diagnosed with HUVS with cardiac valvulopathy, Jaccoud's arthropathy, and MPGN type I. Three daily doses of intravenous methylprednisolone (500mg each) were administered, followed by oral prednisone $(1 \mathrm{mg} / \mathrm{kg} /$ day $)$ and cyclophosphamide $(0.8 \mathrm{mg} / \mathrm{kg} /$ day $)$.

After six months of cyclophosphamide treatment, his treatment was maintained with prednisolone $(15 \mathrm{mg} /$ day), hydroxychloroquine $(400 \mathrm{mg} /$ day), and mycophenolate mofetil (MMF, 1.5g/day). His serum creatinine was $1.56 \mathrm{mg} / \mathrm{dL}$, his urine analysis showed protein $1+$, his red blood cell count was 1 to $3 / \mathrm{HPF}$, and he had a urine protein-creatinine ratio of $291.7 \mathrm{mg} / \mathrm{g}$. He remained markedly hypocomplementemic, and continued with slowly progressive severe arthropathy of the hands, despite improved nephropathy.

\section{Discussion}

HUVS is a rare type of vasculitis first described in 1973 by McDuffie et al. [6] characterized clinically by recurrent urticaria with a variety of systemic manifestations.

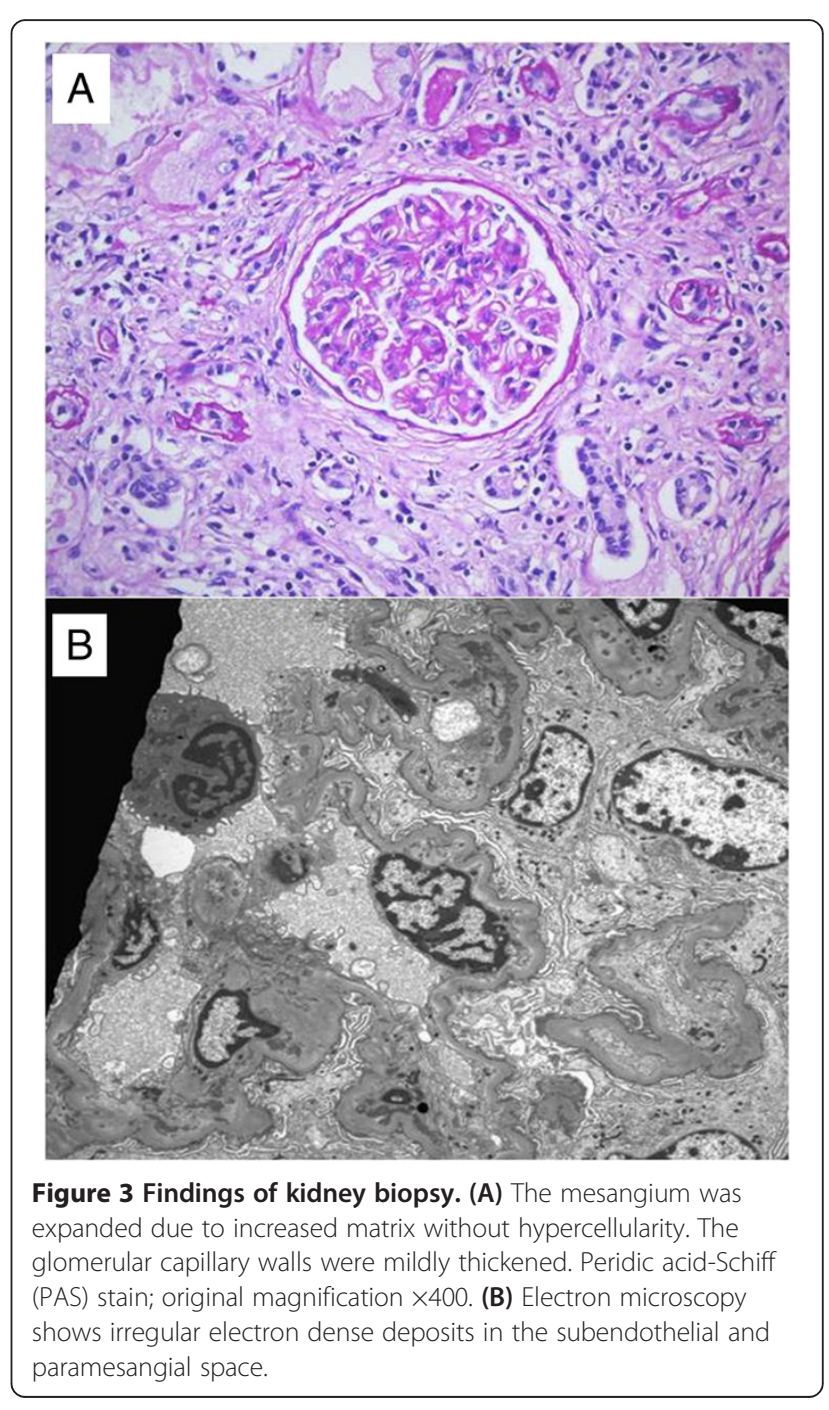


In 1982, Schwartz et al. established the accepted diagnostic criteria [7]. Two major criteria (recurrent urticaria lasting longer than six months and hypocomplementemia) and at least two minor criteria (venulitis on skin biopsy, arthralgias or arthritis, glomerulonephritis, ocular inflammation, abdominal pain, and positive $\mathrm{C} 1 \mathrm{q}$ antibodies) are required for the diagnosis of HUVS. In some patients, HUVS may be secondary to underlying systemic lupus erythematosus (SLE), Sjogren syndrome, or neoplasia $[8,9]$.

Our patient matched the criteria for HUVS on the basis of the clinical findings of recurrent urticaria, arthritis, and abdominal pain, as well as laboratory findings of marked continuous hypocomplementemia and pathological findings of cutaneous vasculitis and glomerulonephritis, in the absence of any other secondary cause.

HUVS primarily occurs in young women, with onset between 23 and 66 years of age with a peak incidence in the fourth decade of life $[1,10]$. Obstructive lung disease, angioedema, ocular inflammation, and glomerulonephritis are common manifestations in HUVS [11]. Lung disease is the principal cause of morbidity and mortality. Wisnieski et al. [1] described 18 patients with HUVS; $50 \%$ of patients had renal involvement that varied from minimal proteinuria to nephrotic syndrome. Six renal biopsies were performed; three cases showed mesangial proliferative glomerulonephritis, two showed MPGN, and one showed membranous nephropathy [1].

There is no consensus on the appropriate treatment of HUVS. Corticosteroid therapy is reportedly effective in many cases of HUVS [11,12], though several cases in adults have progressed to end-stage renal disease [13]. Our patient developed MPGN three years after initial presentation, despite corticosteroid and azathioprine therapy. He continued with progressive worsening of kidney function. He subsequently showed a partial response to a combination of corticosteroids, cyclophosphamide, and MMF.

Some patients with HUVS have had concomitant cardiac valvulopathy and Jaccoud's arthropathy. In 1993, Palazzo et al. described three Caucasian patients with Jaccoud's arthropathy, HUVS, and cardiac valvulopathy [2]. Since 2000, three other patients (an African-American male, a white female, and a Japanese female) have shown this rare combination of symptoms [3-5]. All six of these patients showed no detectable antibodies to $\mathrm{C} 1 \mathrm{q}$ and had no kidney involvement. Our patient had MPGN along with arthropathy, valvulopathy, and HUVS, however, he was not tested for antibodies to C1q.

In 2002, Houser et al. reported the histological findings of the cardiac valves in these patients [14]. His histopathology tests revealed vasculitis with fibrinoid necrosis and granulation tissue with numerous inflammatory cells. One patient showed C1q staining in the valve, and another patient showed prominent deposition of
IgG, IgM, and small amounts of IgA on the valve surface with immunostaining [14].

In the present case, our patient showed extensive immunoglobulin and complement deposition in the glomerular capillary loop. The presence of complement and immunoglobulin in the valvulopathy and glomerulonephritis specimens may be more consistent with damage induced by an immune complex mechanism rather than by an antibody, as in HUVS.

Our patient was the seventh case of the concurrence of HUVS, Jaccoud's arthropathy, and cardiac valvulopathy. He also developed azotemia associated with membranoproliferative glomerulonephritis, unlike other cases. He was treated with a combination of corticosteroids, cyclophosphamide, and MMF, which stabilized his nephropathy. But his cutaneous vasculitis, cardiac valvulopathy, and arthropathy remained unchanged.

\section{Conclusions}

We describe, to the best of our knowledge, the first case of glomerulonephritis along with arthropathy, cardiac valvulopathy, and HUVS. A combination of corticosteroids, cyclophosphamide, and MMF appear to be a safe and effective treatment of nephropathy, however, are less effective for cutaneous vasculitis, cardiac valvulopathy, and arthropathy.

\section{Consent}

Written informed consent was obtained from the patient for publication of this case report and any accompanying images. A copy of the written consent is available for review by the Editor-in-Chief of this journal.

\section{Abbreviations}

ANA: Antinuclear antibodies; anti-CCP: Anti-cyclic citrullinated peptide antibody; ANCA: Antineutrophil cytoplasmic antibody; BUN: Blood urea nitrogen; CT: Computed tomography; ESR: Erythrocyte sedimentation rate; HUVS: Hypocomplementemic urticarial vasculitis syndrome; MMF: Mycophenolate mofetil; MPGN: Membranoproliferative glomerulonephritis; SLE: Systemic lupus erythematosus.

\section{Competing interests}

The authors declare that they have no competing interests.

\section{Authors' contributions}

HCC was in charge of the patient's treatment and care and was principal writer of the manuscript. CP and SWC were involved in the overall care of the patient. JP and JSL were involved in the investigation of data. MK assisted in manuscript preparation. All authors read and approved the final manuscript.

\section{Acknowledgements}

All work done on this report was completed by the authors.

\section{Author details}

'Department of Internal Medicine, Ulsan University Hospital, 290-3 Jeonha-dong, Dong-gu, Ulsan 682-714, Republic of Korea. ${ }^{2}$ Department of Pathology, Ulsan University Hospital, 290-3 Jeonha-dong, Dong-gu, Ulsan 682-714, Republic of Korea. 


\section{References}

1. Wisnieski JJ, Baer AN, Christensen J, Cupps TR, Flagg DN, Jones JV, Katzenstein PL, McFadden ER, McMillen JJ, Pick MA, Richmond GW, Simon SR, Smith HR, Sontheimer RD, Trigg LB, Weldon D, Zone JJ: Hypocomplementemic urticarial vasculitis syndrome. Clinical and serologic findings in 18 patients. Medicine 1995, 74:24-41.

2. Palazzo E, Bourgeois P, Meyer O, De Bandt M, Kazatchkine M, Kahn MF: Hypocomplementemic urticarial vasculitis syndrome, Jaccoud's syndrome, valvulopathy: a new syndromic combination. I Rheumatol 1993, 20:1236-1240

3. Hong L, Wackers F, Dewar M, Kashgarian M, Askenase PW: Atypical fatal hypocomplementemic urticarial vasculitis with involvement of native and homograft aortic valves in an African American man. J Allergy Clin Immunol 2000, 106:1196-1198.

4. Chen HJL, Bloch KJ: Hypocomplementemic urticarial vasculitis, Jaccoud's arthropathy, valvular heart disease and reversible tracheal stenosis: a surfeit of syndromes. J Rheumatol 2001, 28:383-386.

5. Amano H, Furuhata N, Tamura N, Tokano Y, Takasaki Y: Hypocomplementemic urticarial vasculitis with Jaccoud's arthropathy and valvular heart disease: case report and review of the literature. Lupus 2008, 17:837-841.

6. McDuffie FC, Sams WM, Maldonado JE, Andreini PH, Conn DL, Samayoa EA: Hypocomplementemia with cutaneous vasculitis and arthritis. Possible immune complex syndrome. Mayo Clin Proc 1973, 48:340-348.

7. Schwartz HR, McDuffie FC, Black LF, Schroeter AL, Conn DL: Hypocomplementemic urticarial vasculitis. Association with chronic obstructive pulmonary disease. Mayo Clin Proc 1982, 57:231-238.

8. Venzor J, Lee WL, Huston DP: Urticarial vasculitis. Clin Rev Allergy Immunol 2002, 23:201-216.

9. Her MY, Song JY, Kim DY: Hypocomplementemic urticarial vasculitis in systemic lupus erythematosus. J Korean Med Sci 2009, 24:184-186.

10. Buck A, Christensen J, McCarty M: Hypocomplementemic urticarial vascultitis syndrome: a case report and literature review. J Clin Aesthet Dermatol 2012, 5:36-46.

11. Jara $\sqcup$, Navarro C, Medina G, Vera-Lastra O, Saavedra MA: Hypocomplementemic urticarial vascultitis syndrome. Curr Rheumatol Rep 2009, 11:410-415.

12. Sanchez NP, Winkelmann RK, Schroeter AL, Dicken CH: The clinical and histopathologic spectrums of urticarial vasculitis: study of forty cases. Am Acad Dermatol 1982, 7:599-605.

13. Ramirez G, Saba SR, Espinoza L: Hypocomplementemic vasculitis and renal involvement. Nephron 1987, 45:147-150.

14. Houser SL, Askenase PW, Palazzo E, Bloch KJ: Valvular heart disease in patients with hypocomplementemic urticarial vasculitis syndrome associated with Jaccoud's arthropathy. Cardiovasc Pathol 2002, 11:210-216.

doi:10.1186/1752-1947-8-352

Cite this article as: Park et al:: Membranoproliferative glomerulonephritis presenting as arthropathy and cardiac valvulopathy in hypocomplementemic urticarial vasculitis: a case report. Journal of Medical Case Reports 2014 8:352

\section{Submit your next manuscript to BioMed Central and take full advantage of:}

- Convenient online submission

- Thorough peer review

- No space constraints or color figure charges

- Immediate publication on acceptance

- Inclusion in PubMed, CAS, Scopus and Google Scholar

- Research which is freely available for redistribution

Submit your manuscript at www.biomedcentral.com/submit
C Biomed Central 